\title{
STUDI HALUAN KAPAL SELAM BENTUK KAPSUL UNTUK MEMINIMALISIR HAMBATAN GESEK TERHADAP AIR LAUT
}

\author{
Purwo Joko Suranto $^{1)}$ dan Wiwin Sulistyawati ${ }^{2)}$ \\ Fakultas Teknik Program Studi Perkapalan \\ Universitas Pembangunan Nasional "Veteran" Jakarta \\ email: jekdoank@gmail.com ${ }^{l)}$
}

\begin{abstract}
Submarine has been widely used both for military and for underwater research, various models of hull forms including capsule-shaped submarine. From the capsule form is to be modified in order to get bow shape forms the barrier fluid is small, so the use of power the main engine will be smaller and can save fuel. The shape and size of the bow of the submarine models to be analyzed consists of three (3) the shape and size of the different models. Model first (1) shaped like a capsule, the second model (2) measure the same length as the capsule form is only the tip of the bow made a sharp resembles a bullet, the third model (3) the same shape as the second model just the tip of the bow that resembles the size of a bullet extended. Fluid analysis using ANSYS CFD software version 15.0. where modeling and manufacturing of using ICEM CFD meshing, defining domain for the fluid and the boundary layer to limit the fluid domain using CFX-Pre, iteration calculation using CFX Solver Manager while to display the results of calculations using CFD-post. Meshing is used to achieve independent meshing, so if meshing plus will not affect the results obtained. Results Barriers fluid to the model of unity of 294581 Newton, for the second model of 275961 Newton while the third model obtained at 271939 Newton.
\end{abstract}

Keywords : submarine, meshing, iteration, resistance

\section{Pendahuluan}

Kapal selam atau disebut juga Sub Marine sudah banyak digunakan di berbagai negara baik untuk kepentingan militer maupun kepentingan penelitian bawah laut. Penelian pengembangan bentuk body kapal terus berjalan banyak inovasi-inovasi bentuk badan kapal yang sudah tercipta diantaranya bentuk body kapal selam yang menyerupai kapsul.

Bentuk lambung kapal selam dengan model kapsul banyak sekali dan kebanyakan model kapal selam adalah bentuk kapsul.

Bentuk haluan kapal selam atau moncong kapal selam sangatlah penting karena dengan bentuk moncong yang baik maka akan dapat mengurangi hambatan kapal tersebut terhadap fluidanya dalam hal ini air laut. .

Bentuk lambung kapsul inilah yang akan dimodifikasi pada bagian ujung haluan kapal selam sehingga didapat tiga bentuk model haluan kapal selam, ketiga model tersebut akan dianalisa hambatan terhadap fluidanya sehingga bisa diketahui mana dari ketiga model tersebut yang hambatan fluidanya paling kecil.
Dengan hambatan lambung yang kecil maka akan memperkecil pula nilai Horse Power mesin yang akan digunakan sehingga otomatis Bahan Bakar yang digunakan juga akan lebih irit, sehingga dengan Bahan Bakar yang jumlahnya sama maka kapal dapat lebih lama beroperasi di perairan, atau bisa juga kapal beroperasi untuk waktu yang sama tetapi konsumsi Bahan Bakar lebih sedikit.

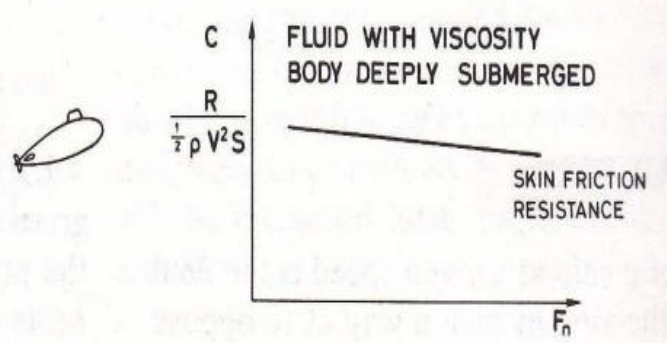

Gambar 1. Koefisien Hambatan Kapal Selam

Untuk itu maka hambatan kapal sangat berperan penting terhadap power mesin yang akan digunakan, menurut William Froude Total Hambatan kapal yang bergerak di fluida adalah sebagai berikut :

$\mathrm{Rt}=\mathrm{Rf}+\mathrm{Rr}$ 
Dimana :

$\mathrm{Rt}=$ Tahanan Gesek

$\mathrm{Rr}=$ Tahanan Sisa

Adapun yang yang dominan dan yang paling bepengaruh serta yang paling besar dari kedua hambatan tersebut adalah hambatan gesek, hambatan ini terjadi karena kapal bergerak di dalam suatu media fluida sehingga terjadi gesekan antara lambung kapal dengan fluida dalam hal ini fluidanya adalah air laut. Maka menurut William Froude Hambatan Gesek adalah sebagai berikut:

$\mathrm{Rf}=\mathrm{f} . \mathrm{S} \cdot \mathrm{V}^{\mathrm{n}}$

\section{Dimana :}

$\mathrm{f}=$ koefisien tahanan gesek

$\mathrm{S}=$ Luas permukaan basah $\left(\mathrm{m}^{2}\right)$

$\mathrm{V}=$ Kecepatan (knots)

Adapun daftar table $\mathrm{f}$ dan $\mathrm{n}$ sebagaimana terlihat pada gambar 2 .

\begin{tabular}{|c|c|c|c|c|}
\hline \multirow{2}{*}{$\begin{array}{c}\text { Nature of } \\
\text { Surface }\end{array}$} & \multicolumn{4}{|c|}{ Length, $L$} \\
\hline & 2 feet & 8 feet & 20 feet & 50 feel \\
\hline \multicolumn{5}{|l|}{ Values for $f^{*}$} \\
\hline Varnish & 0.0117 & 0.0121 & 0.0104 & 0.0097 \\
\hline Paraffin & 0.0119 & 0.0100 & 0.0088 & \\
\hline Calico & 0.0281 & 0.0196 & 0.0184 & 0.0170 \\
\hline Fine Sand & 0.0231 & 0.0166 & 0.0137 & 0.0104 \\
\hline Medium Sand & 0.0257 & 0.0178 & 0.0152 & 0.0139 \\
\hline Coarse Sand & 0.0314 & 0.0204 & 0.0168 & $\ldots \ldots$ \\
\hline \multicolumn{5}{|l|}{ Values for $n$} \\
\hline Varnish & 2.00 & 1.85 & 1.85 & 1.83 \\
\hline Paraffin & 1.95 & 1.94 & 1.93 & \\
\hline Calico & 1.93 & 1.92 & 1.89 & 1.87 \\
\hline Fine Sand & 2.00 & 2.00 & 2.00 & 2.06 \\
\hline Medium Sand & 2.00 & 2.00 & 2.00 & 2.00 \\
\hline Coarse Sand & 2.00 & 2.00 & 2.00 & $\ldots$ \\
\hline
\end{tabular}

\section{Gambar 2. Tabel f dan $n$ menurut Froude}

Begitupun juga dengan kecepatan kapal ini akan mempengaruhi besar kecilnya hambatan kapal juga, semakin cepat kapal tersebut maka hambatan kapalnya semakin besar, semakin kecil kecepatannya maka akan semakin kecil juga hambatan kapalnya sebagai mana terlihat pada gambar 3. Untuk pengujian menggunakan CFD kecepatan Kapal ditetapkan 15 knots.

Semakin hambatanya besar maka penggunaan Horse Power mesin akan besar pula maka akan mengakibatkan kosumsi BBM yg semakin besar. Demikian pula bila hambatan kapal kecil maka Horse Power yang digunakan akan kecil, sehingga dapat memperkecil kosumsi bahan bakar alias lebih irit.

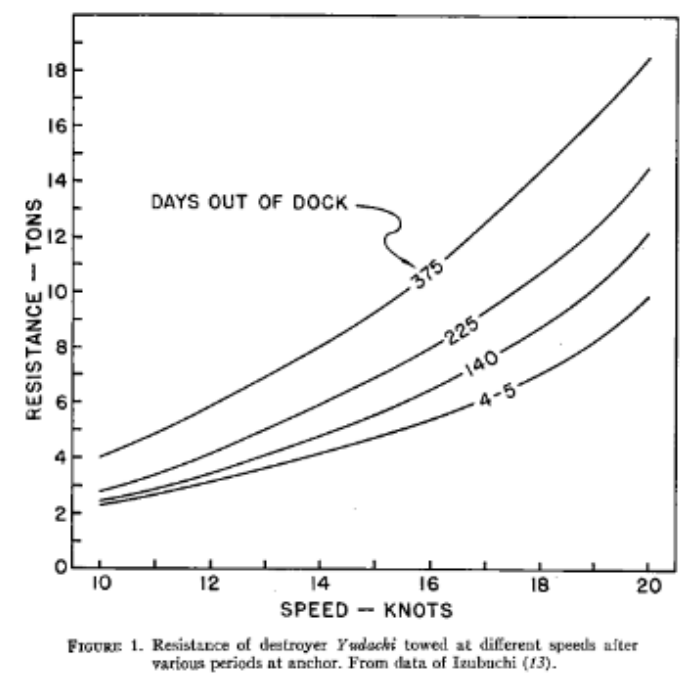

Gambar 3. Grafik Kecepatan dan Hambatan

Pada penelitian ini hambatan kapal hanya akan ditinjau dari segi hambatan yang dominan saja yaitu dari segi hambatan gesek karena hambatan gesek inilah yg paling besar pengaruhnya bila dibanding dengan hambatan sisa yaitu sekitar $87 \%$ untuk kecepatan kapal sebesar 14 knot, berarti hambatan sisanya hanya $13 \%$ saja.

\section{Pemodelan dan meshing independent}

Langkah awal penelitian ini adalah dengan membuat model kapal selam, untuk mempermudah pembuatan model kapal selam maka pelaksanaan pembuatan kapal dengan menggunakan software maxsurf sebagaimana terlihat pada gambar 4, dimana model kapal selam yang sudah dibuat dengan menggunakan software maxsurf dan siap dieksport ke software ANSYS ICEM-CDF ukuran pokoknya adalah sebagai berikut :
Loa $=79.956 \mathrm{~m}$
$\mathrm{B}=11.067 \mathrm{~m}$
$\mathrm{H}=17.177 \mathrm{~m}$

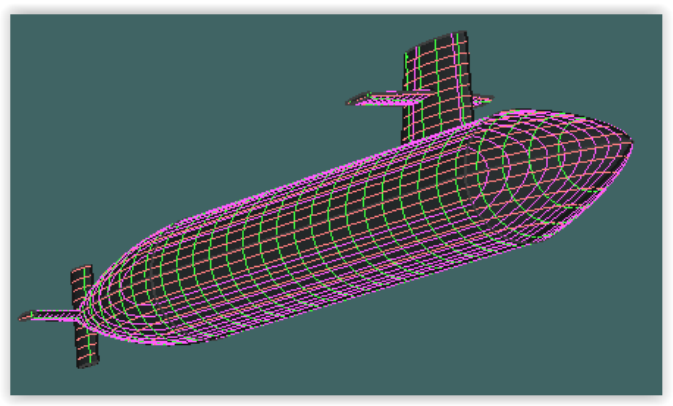

Gambar 4. Model Kapal 
Model tersebut kemudian dieksport ke ANSYS ICEM-CFD untuk dilakukan proses pembuatan element mesh. Meshing dilakukan secara berulang-ulang dimana setiap pengulangan proses dilakukan penambahan mesh dengan cara dinaikan elemen meshnya dua kali lipat hingga sampai didapatkan apa yang disebut dengan meshing independent dimana bila mesh ditambah terus menerus maka jumlah pertambahan mesh tidak akan mempengaruhi secara signikfikan dari hasil yang diproleh.

Sebagaimana ditunjukan pada tabel 1 dan gambar 5, dimana apabila jumlah meshing elemen ditambah atau ditingkatkan dua kali lipat terus menerus, maka tidak akan merubah hasil force secara signifikan.

Tabel 1. Hasil Meshing Independent

\begin{tabular}{|l|c|c|}
\hline & Total Element & $\begin{array}{c}\text { Force Submarine } \\
\text { (Newton) }\end{array}$ \\
\hline Mesh1 & 72606 & 418835 \\
\hline Mesh2 & 155944 & 454308 \\
\hline Mesh3 & 366489 & 387404 \\
\hline Mesh4 & 689700 & 334900 \\
\hline Mesh5 & 1308206 & 300411 \\
\hline Mesh6 & 3453555 & 294581 \\
\hline
\end{tabular}

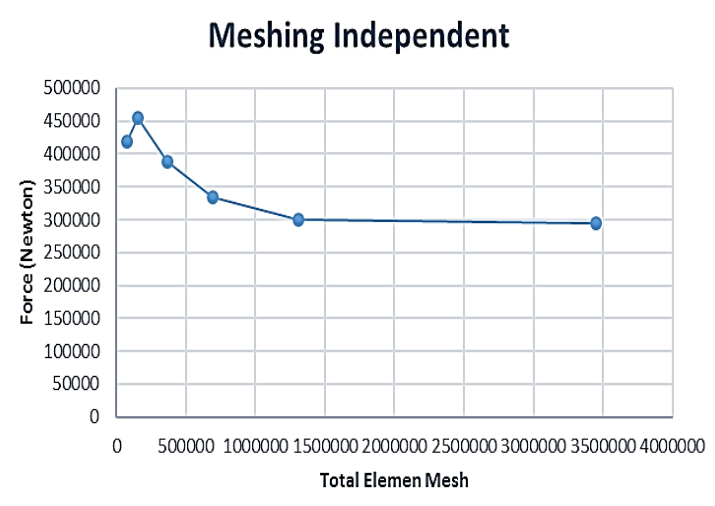

Gambar 5. Meshing Independent

Meshing independent inilah yang digunakan untuk proses meshing selanjutnya untuk tiga (3) buah model kapal selam bentuk kapsul yang dibedakan dari bentuk moncong/ haluannya, jadi ada 3 buah bentuk haluan kapal selam yang terdiri dari tiga bentuk haluan/moncong yang berbeda-beda sebagaimana terlihat pada gambar 6, gambar 7 dan gambar 8.



Gambar 6. Bentuk Haluan 1

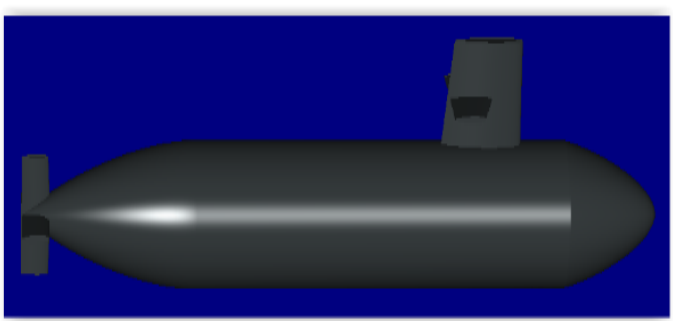

Gambar 7. Bentuk Haluan 2

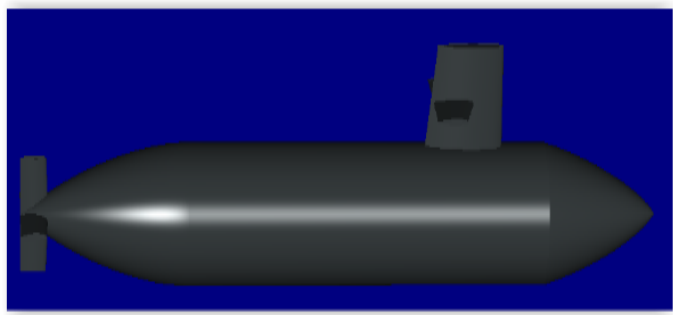

Gambar 8. Bentuk Haluan 3

Ketiga model tersebut dieksport ke dalam software ICEM-CFD untuk dilakukan proses penamaan tiap-tiap bagian seperti, Sub Marine, Box, Fuida, Inlet, Outlet, Wall serta pembuatan elemen-elemen mesh dengan cara meshing sebagaimana terlihat pada gambar 9 .

Meshing adalah pembagian sebuah benda menjadi beberapa bagian bagian kecil elemen. Dalam Metode Elemen Hingga ini disebut dengan diskrititasi, yang mana ini adalah merupakan hal inti dalam penelitian berbasis elemen hingga.

Maka ketiga model harus di meshing terlebih dahulu dengan jumlah pembagian elemen sesuai dengan hasil dari meshing independent, yang mana tujuannya agar proses penghitungan secara iterasi dapat dilakukan dengan baik, sehingga dihasilkan hasil yang akurat.

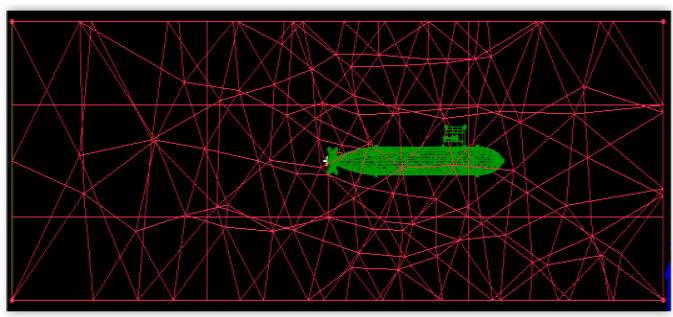

Gambar 9. Meshing in ICEM-CFD 


\section{Boundary Layer.}

Boundary

layer (lapisan batas) sebagaimana gambar 10 adalah suatu lapisan yang terbentuk disekitar penampang yang dilalui oleh fluida tersebut, karena mengalami hambatan yang disebabkan oleh beberapa faktor, seperti faktor gesekan, dan efek- efek viskos.

Viskositas adalah kemampuan untuk menahan suatu gesekan (ukuran kekentalan fluida)

BOUNDARY LAYER ON FLAT PLATE (y scale greatiy enlarged)

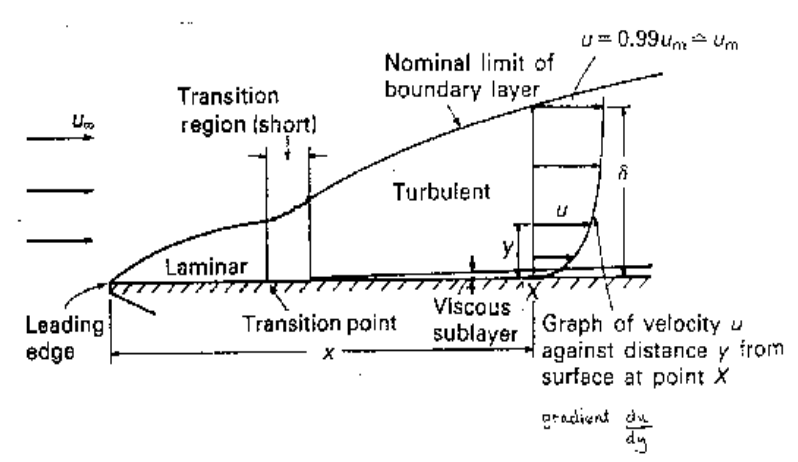

Gambar 10. Boundary Layer



Gambar 11. Boundary Layer in CFX-Pre

Model kapal selam yang akan dianalisa harus di identifikasi batas-batas lapisan (boundary layer) dengan cara pemberian identifikasi bagian demi bagian antara kapal selam dengan fluidanya. Agar nantinya namanama komponen yg akan di iterasi tersebut pada waktu proses iterasi berlangsung, pada CFXSolver dapat membedakan dan memproses penghitungan dengan baik,

Adapun identifikasi penamaan lapisan batas atau boundary layer antara fluida dengan kapal selam, akan dilaksanakan menggunakan ANSYS CFX-Pre. Sebagaimana ditampilkan pada gambar 11

\section{Iterasi}

Proses penghitungan elemen-elemen mesh yang sudah di identifikasi, dimana ketiga model kapal selam satu demi satu di iterasi adapun rumus metode iterasi Gauss-Seidel sebagai berikut:

$x_{i}^{(k)}=\frac{-\sum_{j=1}^{i-1}\left(a_{i j} x_{j}^{(k)}\right)-\sum_{j=i+1}^{n}\left(a_{i j} x_{j}^{(k-1)}\right)+b_{i}}{a_{i j}}$

Tetapi dengan menggunakan CFX-Solver Manager penghitungan iterasi akan lebih cepat dan akurat.

Dimana diseting proses perhitungan iterasi akan berhenti apabila hasil proses penghitungan telah mencapai angka 0.0001 sebagaimana terlihat pada gambar 12 .

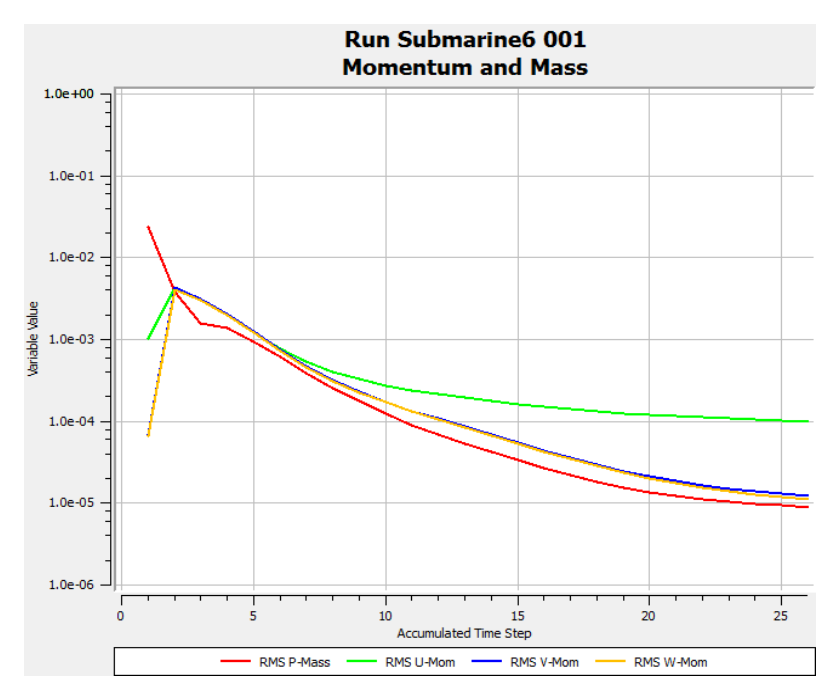

Gambar 12. Grafik iterasi kapal selam.

\section{Hasil}

Setelah proses iterasi berhenti yaitu hasil mencapai 0.0001 , masuk ke proses selanjutnya yaitu menggunakan CFD-Post. Dimana pada CFD-Post dapat ditampilkan output atau hasil yang diinginkan pada tiap-tiap komponen. Komponen yang akan dilihat adalah komponen kapal selam. yang akan dilihat hasil resistance atau hambatan kapal selam terhadap fluidanya dalam hal ini terhadap fluida air laut.

Hasil masing-masing dari ketiga kapal selam adalah sebagai berikut:

a. Kapal selam moncong 1 .

Output dari CFD-Post sebagaimana dapat dilihat pada gambar 13 dapat dilihat aliran fluida dari haluan menuju buritan yang bersentuhan langsung dengan badan kapal, untuk kapal selam dengan bentuk 
moncong 1 diketahui berdasarkan output dari CFD-Post adalah hambatannya sebesar $294581 \mathrm{~N}$.

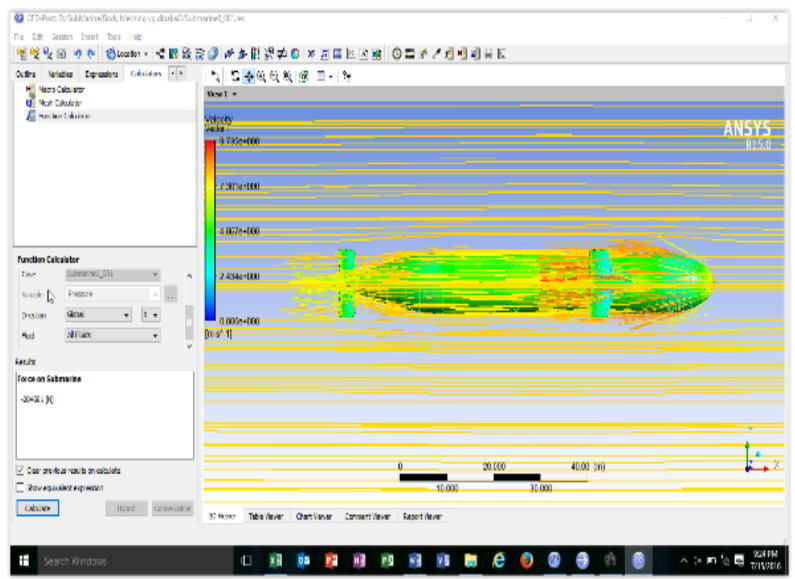

Gambar 13. Grafik iterasi kapal selam.

b. Kapal selam moncong 2 .

Output dari CFD-Post sebagaimana dapat dilihat pada gambar 14 dapat dilihat aliran fluida dari haluan menuju buritan yang bersentuhan langsung dengan badan kapal, untuk kapal selam dengan bentuk moncong 2 diketahui berdasarkan output dari CFD-Post adalah hambatannya sebesar $275961 \mathrm{~N}$.

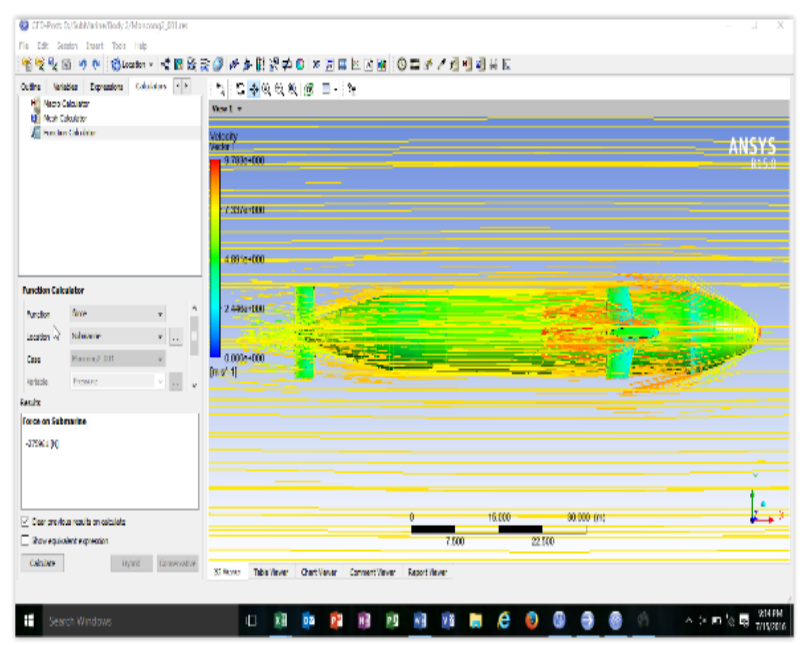

Gambar 14. Grafik iterasi kapal selam.

c. Kapal selam moncong 3.

Output dari CFD-Post sebagaimana dapat dilihat pada gambar 15 dapat dilihat aliran fluida dari haluan menuju buritan yang bersentuhan langsung dengan badan kapal, untuk kapal selam dengan bentuk moncong 3 diketahui berdasarkan output dari CFD-Post adalah hambatannya sebesar $271939 \mathrm{~N}$



Gambar 15. Grafik iterasi kapal selam.

\section{Simpulan}

Sesuai dari tampilan hasil output CFDPost sebagaimana dapat dilihat pada gambar 13, 14 dan 15 bisa disimpulkan dari ketiga output tersebut bahwa kapal selam dengan bentuk moncong 3 sebagaimana terlihat pada gambar 15, mempunyai hambatan kapal terhadap fluidanya adalah paling kecil bila dibanding dengan bentuk moncong 1 dan bentuk moncong 2., dimana hambatan kapalnya adalah sebesar $271939 \mathrm{~N}$.

Sehingga bentuk kapal selam dengan haluan atau moncong 3 seperti diperlihatkan pada gambar 15 tersebut paling baik digunakan untuk kapal selam ditinjau dari hambatan geseknya (Rf) terhadap fluidanya (air laut)

\section{Daftar Pustaka}

ANSYS. (2015). ANSYS CFX Intoduction \& TutorialsANSYS, Inc.

Andrianto, M, 2012, A CFD Modelling on the Slug Flow Mechanism of Air-Water Two Phase Flow in A Horizontal Pipe By Using A VOF Method, Tesis, Jurusan Teknik Mesin dan Industri, Universitas Gadjah Mada, Yogyakarta, Indonesia

Fujiwara, dkk (2003), National Maritime

Research Institute, On Aerodynamic Characteristics of a Hybrid Sail with Square Soft Sail, Tokyo

Endro, W.D. (2014),

High Speed Ship Total ResistanceCalculation (An Empirical Study), JurnalKapal V11, No 1, dkk (2003), National Maritime Research Institute, On Aerodynamic Characteristics of a

Sulisetyono, A., \& Purnomo, D. 2009.The MiniSubmarine Design for Monitoring of the 
Pollutant and Sewage Discharge in Coastal Area.

5th International Conference on Asian and Pacific Coasts. Singapore:NTU

Prisdianto, A., \& Sulisetyono, A.2012.Perancangan ROV dengan Hydrodinamic Performance yang Baik untuk Misi Monitoring Bawah Laut.Surabaya:ITS.

Dyer, Charles. 2002. Fixed Point Iteration.

University of Leeds.

Submarine

Dive Technology, http://www.heiszwolf.com/subs/tech/tech0 1.html diakses 01 Juni 2016.

Froude, W , Froude R.E. , 1888, The Resistance of Ships

Molland, A.F, Turnock, S.R, Hudson,D.A, Ship Resistance and Propulsion Practical Estimation of Propulsive Power

Larsson,L.L, Raven, H.C., 2010, Ship Resistence and Flow, Society of Naval Architects and Marine Engineers

Douglas, J.F, Gasiorek, J.M, and Swaffield, J.A., 2001, Fluid Mechanics 